\title{
STRATEGI PENGEMBANGAN KLASTER BERDASARKAN KINERJA DAN KUALITAS PADA UMKM EMPING JAGUNG DI KABUPATEN LAMONGAN
}

\section{Strategy Development of Cluster Models Based on Performance and Quality in UMKM Corn Chips in Lamongan Regency}

\author{
Siti Asmaul Mustaniroh, Eva Novita Sari ${ }^{*}$, Panji Deoranto \\ Jurusan Teknologi Industri Pertanian, Fakultas Teknologi Pertanian, Universitas Brawijaya \\ Jl. Veteran - Malang 65145 \\ * Penulis Korespondensi, email : evanovitasari555@gmail.com
}

Disubmit: 24 Agustus 2018 Direvisi: 26 April 2019 Diterima: 19 Juni 2019

\begin{abstract}
ABSTRAK
Kabupaten Lamongan merupakan salah satu wilayah di Jawa Timur yang memiliki potensi di sektor pertanian. Banyaknya jagung di kecamatan Lamongan menjadi peluang untuk diolah menjadi emping jagung yang berpotensi menjadi produk unggul daerah. Tujuan dari penelitian ini menentukan strategi terbaik untuk tiap klaster yang terbentuk. Metode yang digunakan yakni K-means Cluster dan Fuzzy Analytic Hierarchy (FAHP). Pada model pengembangan klaster agroindustri diperoleh 2 klaster berdasarkan berdasarkan kinerja dan kualitas produk UKM emping jagung di Kabupaten Lamongan. Pada klaster 1 merupakan usaha skala kecil yang terdiri 3 UKM emping jagung, faktor yang gunakan adalah kualitas UKM $(0,57)$ dengan kriteria performance product $(0,32)$ sehingga alternatif yang dapat digunakan adalah meningkatkan kualitas tenaga kerja, menentukan dan menerapkan standarisasi produksi dan menerapkan teknologi tepat guna $(0,26)$. Klaster 2 merupakan usaha skala mikro yang terdiri dari $5 \mathrm{UKM}$, hasil penelitian menunjukkan bahwa klaster 2 faktor yang berpengaruh adalah kinerja UKM $(0,51)$ dengan kriteria permasalahan yang mempengaruhi strategi pengembangan klaster adalah tenaga kerja $(0,30)$ sehingga alternatif yang dapat digunakan adalah meningkatkan kualitas tenaga kerja $(0,35)$.
\end{abstract}

Kata kunci: Kinerja dan Kualitas; Klaster; Strategi.

\begin{abstract}
Lamongan regency is one of the areas in East Java that has potential in the agricultural sector. The large amount of corn in Lamongan district is an opportunity to be processed into corn chips which has the potential to be a superior product of the region. The purpose of this study is to determine the best strategy for each cluster formed. The method used is K-means Cluster and Fuzzy Analytic Hierarchy (FAHP). The agroindustry cluster development model obtained 2 clusters based on the performance and product quality of SME corn chips in Lamongan regency. In cluster 1 is a small scale business consisting of 3 corn chips $S M E s$, the factor used is the quality of SMEs (0.57) with performance product criteria (0.32) so that an alternative that can be used is to improve the quality of labor, determine and implement production standards and applying appropriate technology (0.26). Cluster 2 is a micro scale business consisting of 5 $S M E s$, the results of the study show that cluster 2 factors that influence is the performance of SMEs (0.51) with the criteria for the problem affecting the cluster development strategy is labor (0.30) so that alternatives can be used is improving the quality of labor (0.35).
\end{abstract}

Keywords : Cluster; Performance and Quality; Strategy. 


\section{PENDAHULUAN}

Agroindustri di provinsi Jawa Timur melakukan pengolahan pada hasil pertanian dengan harapan memperoleh nilai tambah dan menumbuhkan kegiatan ekonomi daerah. Pola pertumbuhan negara menunjukkan bahwa pangsa sektor industri pengolahan meningkat cepat, sehingga perlu dilakukan pengembangan sektor agroindustri di Jawa Timur, hingga saat ini peyumbang terbesar terhadap Produk Domestik Regional Bruto (PDRB) Jawa Timur adalah Usaha Mikro Kecil Menengah (UMKM). Sumbangannya sangat besar menguasai $54,98 \%$ terhadap PDRB Jatim. Sumbangan UMKM pada PDRB Jawa Timur mencapai Rp 900 triliun mulai Januari hingga Agustus 2016. Jumlah itu lebih besar dibanding Januari hingga Oktober 2015, yakni sebesar Rp 1.100 triliun. Rata-rata perkembangan UMKM di Jawa Timur sebesar $54,34 \%$ per tahun.

Pada pengembangan UMKM perlu memperhatikan juga pengembangan agroindustri, hal ini karena pengembangan agroindustri bertujuan mempererat kerjasama antara pihak pertanian dengan pihak industri, sehingga dalam hal ini diharapkan dapat meningkatkan nilai tambah suatu produk pertanian. Pengembangan agroindustri sangat diperlukan karena suatu sektor pertanian sangat memerlukan industri ekstraktif (industri yang bahan baku utamanya terdapat di alam dan diambil secara langsung) yang mana industri tersebut diharapkan dapat mengolah seluruh hasil dari pertanian (Nugrahaning, 2012). Kabupaten Lamongan berupaya mengembangkan UMKM dan sentrasentra industri potensial dengan tujuan untuk meningkatkan ekonomi daerah di Kabupaten Lamongan melalui penerapan konsep One Village One Product (OVOP).

Mengacu pada program One Village One Product (OVOP) dikeluarkan melalui Instruksi Presiden (INPRES) No. 6 Tahun 2007 tanggal 8 Juni, pemerintah mengeluarkan Rencana Pembangunan Jangka Menengah Daerah (RPJMD) tahun 2015-2019 melakukan klaster di seluruh wilayah Jawa Timur salah satunya di Kabupaten Lamongan. Peningkatan jumlah industri kecil atau UKM di Kabupaten Lamongan diharapkan mampu meningkatkan daya saing industri produk unggulan secara global yang berimbas pada peningkatan pendapatan perekonomian daerah. Klaster industri telah menjadi suatu kebijakan pemerintah Indonesia dengan tujuan memperkuat struktur industri Indonesia. Perkembangan klaster industri hingga saat ini belum menunjukkan hasil yang signifikan, yang dapat memperkuat struktur industri (Tmava et al., 2013).

Menurut Iwuagwu (2011) konsep klaster memfokuskan pada strategi untuk mencapai produktivitas suatu usaha. Permasalahan UKM hingga saat ini yakni kurangnya fasilitas kredit, pemanfaatan kapasitas yang buruk, tenaga kerja yang kurang terampil memerlukan adanya konsep klaster. Konsep klaster dapat menciptakan komunikasi pada suatu usaha untuk meningkatkan kinerja usaha, daya saing perdagangan global yang efektif

Pada penelitian ini pengembangan UKM emping jagung dikelompokkan berdasarkan kinerja UKM dan kualitas produk dengan menggunakan analisis klaster. Kinerja UKM adalah pertumbuhan pada suatu UKM yang dinilai dari pertumbuhan unit usaha serta tenaga kerja. Kinerja UKM emping jagung mencakup kapasitas produk, jumlah tenaga kerja, ratarata penjualan, investasi awal, lama produksi dan jumlah cacat produk pada setiap kali proses produksi. Variabel kualitas produk yang digunakan yakni performance, feature, reliability, conformance to specification, durability dan perceived quality. Aspek dalam kualitas tersebut dianggap penting karena mewakili kondisi produk emping jagung di Kabupaten Lamongan.

Penelitian ini mengelompokkan beberapa UKM produksi emping jagung dengan variabel-variabel yang memiliki kesamaan menggunakan analisis K-means cluster. Pada metode ini fokus pada pengelompokan berdasarkan variabel yang memiliki kesamaan (Setyaningsih, 2012). Data-data yang telah didapatkan dapat dikelompokan ke dalam beberapa cluster berdasarkan kemiripan dari data-data tersebut, sehingga data-data yang memiliki karakteristik yang sama dikelompokan dalam satu cluster dan yang memliki karakteristik yang berbeda dikelompokan dalam cluster yang lain yang memiliki karakteristik yang sama. 


\section{METODE}

Pada penelitian ini mengacu pada usaha emping jagung di Kabupaten Lamongan yang berjumlah 8 UKM. UKM emping jagung berada di 3 kecamatan yakni kecamatan Kedungpring, Modo dan Solokuro. Terdapat 2 varibel yang digunakan yakni kinerja UKM dan kualitas produk. Pada kinerja terdiri dari kapasitas produk, lama usaha, rata-rata penjualan, tenaga kerja dan investasi awal. Pada kualitas produk terdiri dari performance, feature, conformance to specifications, durability dan perceived quality.

Metode yang digunakan yakni metode elbow dan K-means cluster, dengan menggunakan program R-studio dan SPSS 17.0 for Windows. Menurut Purnima dan Arvind (2014) metode elbow memiliki fungsi untuk mentukan jumlah klaster untuk memperoleh pemodelan data yang jauh lebih baik. Clustering merupakan bagian terpenting dari analisis data. K-means termasuk teknik clustering tertua yang dianggap secara efektif dalam kecepatan pengelompokan dan akurasi data (Kane dan Nagar, 2012).

Data dilakukan uji validitas dan reliabilitas pada data kualitas produk dengan menggunakan SPSS 17.0 for Windows. Hasil dari kualitas produk dinyatakan valid, hal ini karena nilai $\mathrm{r}$ hitung $>\mathrm{r}$ tabel. Pada uji reliabilitas seluruh variabel kualitas dinyatakan reliabel, hal ini karena semua nilai alpha cronbach $\geq 0,06$.

Pada penelitian ini menggunakan analisis klaster non-hierarki dengan metode $\mathrm{K}$ means clustering. Sebelum melakukan analisis klaster dilakukan normalisasi atau standarisasi data. Metode yang digunakan adalah normalisasi Min-Max dengan melakukan transformasi linier terhadap data asli. Tools Rstudio digunakan sebagai alat bantu dalam normalisasi data. Setelah dilakukan normalisasi maka sudah dipastikan bahwa setiap variabel pada UKM sudah standar. Sehingga dalam hal ini dapat dilakukan tahap selanjutnya yakni penentuan jumlah klaster. Penentuan jumlah klaster menggunakan metode elbow (Kodinariya dan Makwana, 2013). Pada metode elbow nilai cluster terbaik yang akan diambil dari nilai Sum of Square Error (SSE) yang mengalami penurunan yang signifikan dan berbentuk siku. hasil cluster tersebut yang paling optimal (Syakur, 2018).

\section{HASIL DAN PEMBAHASAN}

Sebagian wilayah daerah Kabupaten Lamongan merupakan daerah kapur yang sangat cocok ditanami palawija salah satunya jagung. Jagung merupakan salah satu produk unggulan komoditas hasil pertanian di Kabupaten Lamongan, hal ini menjadi peluang untuk mengolah jagung agar memperoleh nilai tambah. Jagung di Kabupaten Lamongan hingga saat ini hanya dijual langsung tanpa adanya proses pengolahan, sehingga keuntungan yang diperoleh rendah. Salah satu upaya yang dilakukan oleh dinas di Kabupaten Lamongan yakni dengan melakukan pengolahan jagung menjadi produk emping jagung. Pemerintahan di Kabupaten Lamongan menerapkan program OVOP pada produk emping jagung menjadi produk unggulan daerah di Kabupaten Lamongan.

Pengembangan agroindustri emping jagung di Kabupaten Lamongan memerlukan kelembagaan klaster industri yang berfungsi untuk menghubungkan antar UKM emping jagung dan juga pihak-pihak terkait, sehingga dapat meningkatkan keunggulan kompetitif serta terjalin hubungan positif antara industri inti dengan industry pendukung. Pemerintahan di Kabupaten Lamongan melihat potensi UKM emping jagung yang dapat dikembangkan untuk meningkatkan perekonomian daerah mengacu pada konsep OVOP. Konsep OVOP merupakan suatu kebijakan untuk mengklasterisasi produk unggulan pada tiap daerah yang bertujuan untuk menonjolkan potensi tiap daerah agar dapat dikembangkan dan mengakses pasar lebih luas lagi.

UKM emping jagung di Kabupaten Lamongan berpotensi menjadi produk unggulan di Kabupaten Lamongan, namun UKM emping jagung masih perlu dikembangkan. Terdapat beberapa pihak yang memiliki peranan penting dalam pengembangan UKM emping jagung. Keterkaitan UKM dengan pihak-pihak ini digambarkan pada kelembagaan klaster industri emping jagung yang ditunjukkan pada Gambar 1. 


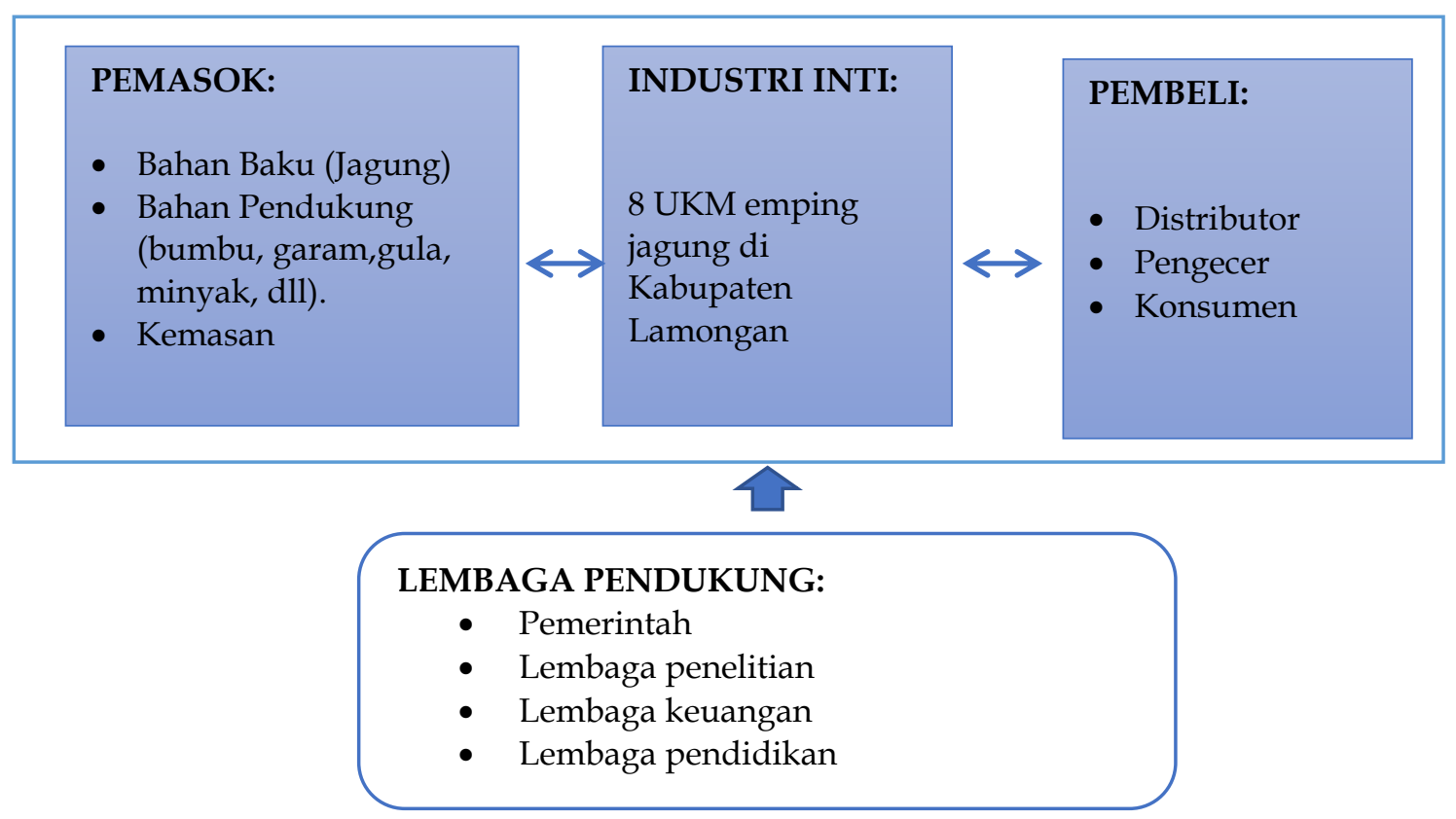

Gambar 1. Skema kelembagaan klaster industri UKM emping jagung

Skema kelembagaan klaster industri UKM emping jagung di Kabupaten Lamongan menggambarkan keterkaitan antar lembaga mulai pengadaan bahan baku hingga produk sampai ke tangan pembeli akhir (konsumen). Adapun elemen atau lembaga yang berpengaruh pada pembangan UKM emping jagung yakni pemasok, industri inti, pembeli dan lembaga pendukung (pemerintah, lembaga penelitian, koperasi, lembaga pendidikan dan lembaga keuangan).

Bahan baku yang digunakan pada proses pembuatan emping jagung berasal dari pemasok di Kabupaten Lamongan. Kedekatan jarak bahan baku dengan UKM mempengaruhi biaya yang dikeluarkan, sehingga biaya yang dikeluarkan untuk bahan baku menjadi rendah. Setiap UKM emping jagung memerlukan jagung kering sebanyak 3500-900 $\mathrm{kg} / \mathrm{bln}$ untuk proses produksi. Pengadaan bahan baku utama dilakukan oleh pemasok jagung yang terdiri dari petani jagung dan KUD di Kabupaten Lamongan. Pada proses pembuatan emping jagung memerlukan bahan pendukung yakni bumbu, garam, gula, minyak dan kemasan. Bahan pendukung diperoleh dari pasar, karena umumnya bahan pendukung mudah diperoleh dan tidak diperlukan dalam jumlah besar. Kemasan yang digunakan pada produk emping jagung memiliki berbagai variasi mulai dari plastik, aluminium foil, kertas atau karton. Terdapat berbagai variasi ukuran produk mulai dari 100gram, 200 gram, 250 gram, $1 \mathrm{~kg}$ dan dalam bentuk curah untuk diekspor. Menurut Abdollahbeigi dan Shahidisadr (2013) inovasi kemasan tidak hanya berperan sebagai daya tarik saja namun inovasi kemasan juga memiliki peranan untuk menunda proses oksidasi, mengendalikan kelembaban, pertumbuhan mikroba, tingkat respirasi dan aroma.

Industri inti merupakan suatu elemen terpenting yang menjadi pusat suatu kegiatan proses pengolahan jagung menjadi emping jagung, terdiri dari 8 UKM emping jagung di Kabupaten Lamongan. UKM emping jagung yang ada di Kabupaten Lamongan berada di 3 kecamatan yakni di kecamatan Kedungpring, Modo dan Solokuro. Industri inti berhubungan langsung pada pemasok, pembeli dan lembaga pendukung untuk pertukaran aliran informasi, dana maupun produk. Pemasok berhubungan langsung dengan industri inti sebagai penyedia bahan baku, terdapat aliran bolak-balik pada pemasok dan industri inti. Pemasok memberikan barang kepada industri inti dan industri inti memberikan aliran dana kepada pemasok. Menurut (Akindipe, 2014) pemasok memiliki peranan yang penting dalam pengadaan bahan baku, dengan adanya pemasok memudahkan dalam pengadaan bahan baku. 
Pembeli berhubungan langsung pada industri inti, terdapat aliran barang dan uang pada transaksi antara pembeli dengan industri inti. Menurut (Susanti, 2018) pembeli memiliki pengaruh besar terhadap UKM dengan meningkatnya pembelian maka keuntungan yang diperoleh juga semakin besar, sehingga diperlukan pasar yang luas agar memudahkan pembeli memperoleh produk.

Pembeli merupakan pihak terakhir dalam alur klaster industri. Pembeli pada UKM emping jagung memiliki 2 jenis yakni pembeli yang melakukan pembelian untuk di konsumsi atau untuk dijual kembali. Adapun beberapa pembeli yang terdapat pada kelembagaan klaster industri emping jagung yakni distributor, pengecer dan konsumen. Distributor berperan sebagai penyalur produk ke tangan konsumen. Menurut Alexandersson dan Fridolf (2015) mengatakan bahwa distributor memiliki peranan penting sebagai media penyalur pada masyarakat. Pengecer merupakan salah satu pembeli yang melakukan proses pembelian produk untuk diperjualkan kembali. Perbedaan distributor dengan pengecer adalah daya beli yang dilakukan. Distributor biasanya melakukan pembelian dalam jumlah perbulannya sedangkan pengecer melakukan pembeli tidak menentu dengan kapasitas yang sedikit. Konsumen merupakan pembeli untuk dirinya sendiri, sehingga pembelian dilakukan sesuai dengan keinginannya. Konsumen dapat langsung membeli produk ke UKM secara langsung dengan tujuan untuk memperoleh harga yang lebih murah.

Lembaga pendukung merupakan suatu elemen yang berperan untuk membantu serta mendukung perkembangan UKM emping jagung di Kabupaten Lamongan. Pemerintah mencakup dinas baik di Jawa Timur maupun di Kabupaten Lamongan dan Bea Cukai. Pemerintah juga ikut serta memantau perkembangan UKM yang berada di Jawa Timur salah satunya di Kabupaten Lamongan. Mengacu pada program OVOP dikeluarkan melalui Instruksi Presiden (INPRES) No. 6 Tahun 2007 tanggal 8 Juni, pemerintah mengeluarkan Rencana Pembangunan Jangka Menengah Daerah (RPJMD) tahun 2015-2019 melakukan klaster di seluruh wilayah Jawa Timur salah satunya di Kabupaten Lamongan.

Lembaga penelitian dan informasi yakni mencakup Badan Penelitian dan Pengembangan Daerah (balitbang), memiliki peranan yakni membantu jalannya program pemerintah serta mendukung pengembangan UKM emping jagung di Kabupaten Lamongan. Badan Penelitian dan Pengembangan Daerah (balitbang) perperan dalam mematau serta mendampingi jalannya program RPJMD tahun 2015-2019. Pentingnya peran lembaga litbang tersebut terangkum pada UU No 23 Tahun 2014 tentang Pemerintahan Daerah yang tercantum pada Pasal 209 dan 219.

Terdapat 2 macam lembaga keuangan diantaranya yakni koperasi dan bank. Koperasi memiliki berbagai peranan salah satunya aliran modal, sehingga apabila UKM mengalami kekurangan modal pihak Koperasi dapat memberikan pinjaman dengan dengan bunga kecil. Bank memiliki peranan yang sama dengan Koperasi yakni memberikan bantuan modal, namun bedanya bank dapat memberikan pinjaman yang lebih besar namun dengan jaminan tertentu dan bunga diatas bunga koperasi. Menurut Tmava et al. (2013) akses ke sumber eksternal melalui pinjaman bank merupakan faktor penting yang mempengaruhi investasi pertumbuhan UKM. Lembaga pendidikan salah satunya yakni Institusi Pendidikan atau Perguruan Tinggi memiliki peran penting sebagai katalisator dalam pengembangan klaster. Perguruan tinggi berperan dalam pendidikan dan menjadi pemain kunci dalam memajukan lembaga riset dan pengembangan suatu klaster.

Berdasarkan metode elbow semakin besar selisih penurunan Sum of Square Error antar $k$ dan berberntuk siku berdasarkan grafik (Bakhtiar dkk., 2016). Adapun hasil perhitungan nilai SSE pada tiap klaster dapat dilihat pada Tabel 1.

Tabel 1. Hasil Uji SEE

\begin{tabular}{crr}
\hline $\begin{array}{c}\text { Jumlah } \\
\text { Klaster }\end{array}$ & \multicolumn{1}{c}{ SSE } & Selisih \\
\hline 1 & 15,98789396 & \\
2 & 1,29580546 & $\mathbf{1 4 , 6 9 2 0 9}$ \\
3 & 0,62359107 & 0,672214 \\
4 & 0,30827343 & 0,315318 \\
\hline
\end{tabular}

Sumber: Data Primer diolah (2018)

Pada perhitungan tersebut dapat dilihat bahwa klaster yang mengalami penurunan drastis dengan selisih terbesar terletak pada klaster 2 yakni yakni dengan 
nilai 14,69209 dan klaster 3 yakni dengan nilai 0,672214. Selanjutnya yakni, melakukan perhitungan nilai withim sum of square by cluster dari 2 dan 3 klaster yang memiliki selisih cukup besar. Terdapat nilai withim sum of square by cluster dari 2 segmen bernilai 91,9\%, sedangkan pada 3 segmen nilainya sebesar $83,9 \%$. Nilai nilai Sum of Square Error (SSE) pada 2 segmen lebih optimal, hal ini karena nilai 2 segmen lebih rendah.

K-means clustering memiliki beberapa aturan yaitu jumlah klaster yang perlu di masukkan dan hanya memiliki atribut numerik. Hasil analisis klaster menunjukkan jumlah anggota klaster 1 sebanyak 3 UKM dan jumlah anggota kalster 2 sebanyak 5 UKM.

Tabel 2. Karakteristik UKM masing-masing Klaster

\begin{tabular}{|c|c|c|c|c|c|c|c|}
\hline \multirow[t]{2}{*}{ No. } & \multirow[t]{2}{*}{ Karakteristik } & \multicolumn{3}{|c|}{ Klaster 1 (3 UKM) } & \multicolumn{3}{|c|}{ Klaster 2 (5 UKM) } \\
\hline & & $\begin{array}{c}\text { Pusat } \\
\text { Klaster }\end{array}$ & Minimal & Maksimal & $\begin{array}{c}\text { Pusat } \\
\text { Klaster }\end{array}$ & Minimal & Maksimal \\
\hline & Kinerja UKM & & & & & & \\
\hline 1. & $\begin{array}{l}\text { Kapasitas produksi } \\
(\mathrm{kg} / \mathrm{bln})\end{array}$ & 3233 & 3000 & 3500 & 1120 & 900 & 1500 \\
\hline 2. & Lama usaha (thn) & 13 & 10 & 16 & 5 & 5 & 5 \\
\hline 3. & Jumlah tenaga kerja & 11 & 8 & 15 & 2 & 2 & 3 \\
\hline 4. & $\begin{array}{l}\text { Rata-rata penjualan } \\
\text { (Rp) }\end{array}$ & 97.000 .000 & 90.000 .000 & 105.000 .000 & 33.600 .000 & 27.000 .000 & 45.000 .000 \\
\hline 5. & Lama produk (hari) & 6 & 6 & 7 & 5 & 5 & 5 \\
\hline 6. & Investasi awal (Rp) & 21.000 .000 & 18.000 .000 & 25.000 .000 & 4.800 .000 & 4.000 .000 & 6.000 .000 \\
\hline & Kualitas Produk & & & & & & \\
\hline 1. & Kinerja (Performance) & 3,8722 & 3,69 & 4,03 & 2,2767 & 2,04 & 2,58 \\
\hline 2. & Fitur (Feature) & 3,9250 & 3,60 & 4,42 & 2,3500 & 2,16 & 2,54 \\
\hline 3. & $\begin{array}{l}\text { Kesesuaian dengan } \\
\text { spesifikasi } \\
\text { (Conformance to } \\
\text { specifications) }\end{array}$ & 3,7185 & 3,61 & 3,86 & 2,6156 & 2,53 & 2,66 \\
\hline 4. & $\begin{array}{l}\text { Daya tahan } \\
\text { (Durability) }\end{array}$ & 3,8889 & 3,83 & 3,97 & 2,5667 & 2,50 & 2,65 \\
\hline 5. & $\begin{array}{l}\text { Kualitas yang } \\
\text { dipersepsikan } \\
\text { (Perceived quality) }\end{array}$ & 3,7296 & 3,66 & 3,76 & 2,1356 & 2,06 & 2,19 \\
\hline
\end{tabular}

Sumber: Data Primer diolah, 2018

Klaster 1 terdiri dari 3 UKM dan klaster 2 terdiri dari 5 UKM. Klaster 1 termasuk skala kecil, sedangkan klaster 2 termasuk skala mikro. Undang-Undang Nomor 20 Tahun 2008 tentang UMKM Pasal 1 angka 1 yang dimaksud dengan usaha mikro adalah usaha produktif milik orang atau perseorangan dan/atau badan usaha perseorangan yang mempunyai kriteria sebagai berikut: memiliki kekayaan paling banyak Rp 50.000.000,00 (lima puluh juta rupiah) tidak termasuk tanah dan bangunan tempat usaha, atau memiliki hasil penjualan tahunan paling banyak Rp 300.000.000,00 (tiga ratus juta rupiah). Sedangkan kriteria usaha kecil adalah sebagai berikut: usaha ekonomi produktif yang bediri sendiri yang dilakukan oleh orang perseorangan atau badan usaha yang bukan merupakan anak perusahaan atau cabang perusahaan yang dimiliki, dikuasai, atau menjadi bagian baik langsung maupun tidak langsung dari usaha menengah atau usaha besar yang memenuhi kriteria sebagai berikut: memliki kekayaan bersih lebih dari Rp 50.000.000,00 (lima puluh juta rupiah) sampai dengan paling banyak Rp 500.000.000,00 (lima ratus juta rupiah) tidak termasuk tanah dan bangunan tempat usaha atau memiliki penjualan tahunan lebih dari $\operatorname{Rp}$ 300.000.000,00 (tiga ratus juta rupiah) sampai dengan paling banyak Rp 2.500.000.000,00 (dua milyar lima ratus juta rupiah). 
Klaster 1 sebagian UKM sudah memiliki sertifikat izin usaha dan persyaratan legalitas berupa PIRT, sertifikat penyuluhan keamanan pangan, sertifikat jaminan mutu dan halal serta memliliki NPWP. Selain itu, klaster 1 sudah melakukan administrasi keuangan dan sebagian sudah mengakses ke perbankan dalam keperluan modal namun sebagian besar belum membuat manajemen usaha dengan baik seperti business planning. Klaster 2 hanya memiliki PIRT serta belum melakukan administrasi keuangan dengan baik dan belum mengakses ke perbankan dalam keperluan modal. Pada umumnya, pengusaha kecil menggantungkan diri pada uang (tabungan) sendiri atau dana pinjaman dari sumbersumber informal untuk kebutuhan modal kerja. Kendala yang umumnya dialami oleh UMKM adalah adanya keterbatasan modal, kesulitan dalam pemasaran dan penyediaan bahan baku, pengetahuan yang minim tentang dunia bisnis, keterbatasan penguasaan teknologi, kualitas SDM (pendidikan formal) yang rendah, manajemen keuangan yang belum baik, tidak adanya pembagian tugas yang jelas, serta sering mengandalkan anggota keluarga sebagai pekerja tidak dibayar

Pada metode sebelumnya menggunakan K-means clustering yang diperoleh beberapa kondisi yang dijadikan sebagai dasar dalam penentuan strategi pengembangan UKM di Kabupaten Lamongan dengan menggunakan FAHP (Fuzzy Analytic Hierarchy Process). Hasil dari K-means clustering menghasilkan 2 klaster, sehingga terdapat 2 strategi pengembangan UKM di Kabupaten Lamongan. Pada struktur hierarki klaster 1 dan klaster 2 terdapat 3 level yakni faktor, kriteria dan alternatif. Pada tiap level terdapat variabel-variabel yang berfungsi untuk membantu meningkatkan strategi pengembangan di Kabupaten Lamongan. Penentuan bobot prioritas dilakukan pada 3 pakar ahli yakni; dinas perindustrian, dinas UMKM dan pemilik UKM. Hasil penilaian pakar yang telah diperoleh kemudian dilakukan pengukuran tingkat konsistensi
/Consistency Ratio (CR). Besaran konsistensi hasil pembobotan pakar pada tingkat kepercayaan sebesar $90 \%$ atau dengan tingkat toleransi hingga 10\% (Wang dan Chin, 2011). Nilai bobot yang telah dilakukan pengukuran CR, maka selanjutnya dilakukan pengintegrasian tingkat kepentingan ke dalam bilangan Triangular Fuzzy Numerik (TFN). Nilai yang telah diubah menjadi skala TFN, selanjutnya dilakukan defuzzifikasi sesuai nilai lower, middle dan upper. Hasil defuzzifikasi akan dihitung nilai sintesis fuzzy (Si) prioritas. Menentukan nilai vektor $(V)$ dan nilai ordinat defuzzifikasi dengan sistem perbandingan silang antara nilai upper dan lower dengan menggunakan sintesis fuzzy (Zhang et al., 2014). Langkah berikutnya yakni melakukan normalisasi nilai vektor untuk memperoleh bobot kriteria tahapan-tahapan ini dilakukan tiap tingkatan level pada hirarki.

Penyusunan pengembangan masingmasing klaster menggunakan struktur hierarki dan pakar yang sama. Permasalahan yang ada di UKM emping jagung di Kabupaten Lamongan digambarkan berdasarkan struktur hierarki. Pada Gambar 2 dapat dilihat hasil dari bobot tiap komponen yang ada pada tiap level. Pada pengembangan strategi klaster 1 terdapat 3 komponen yang mempengaruhi strategi dalam pengaplikasian stretegi. Adapun 3 komponen tersebut yakni faktor, kriteria dan alternatif.

Permasalahan yang ada di UKM emping jagung di Kabupaten Lamongan digambarkan berdasarkan struktur hierarki. Terdapat 3 level dan beberapa komponen pada tiap level. Pada Gambar 3 dapat dilihat hasil dari bobot tiap komponen yang ada pada tiap level. Pada pengembangan strategi klaster 2 terdapat 3 komponen yang mempengaruhi strategi dalam pengaplikasian stretegi. Adapun 3 komponen tersebut yakni faktor, kriteria dan alternatif. 
Jurnal Teknologi Pertanian Vol. 20 No. 2 [Agustus 2019] 85-94

Strategi Pengembangan Klaster Berdasarkan Kinerja dan Kualitas [Sari dkk]

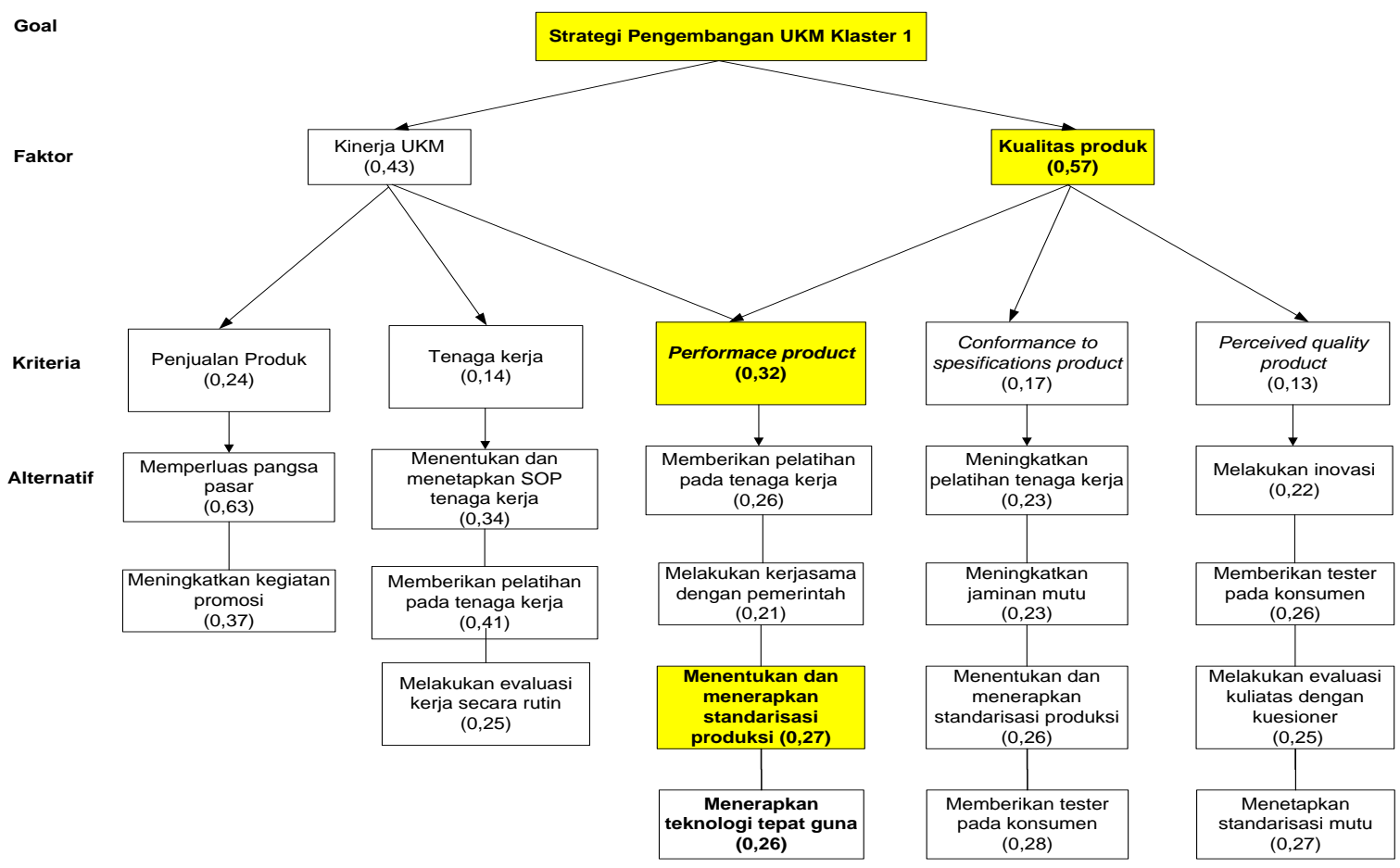

Gambar 2. Hirarki dan prioritas strategi pengembangan ukm klaster 1 di Kabupaten Lamongan

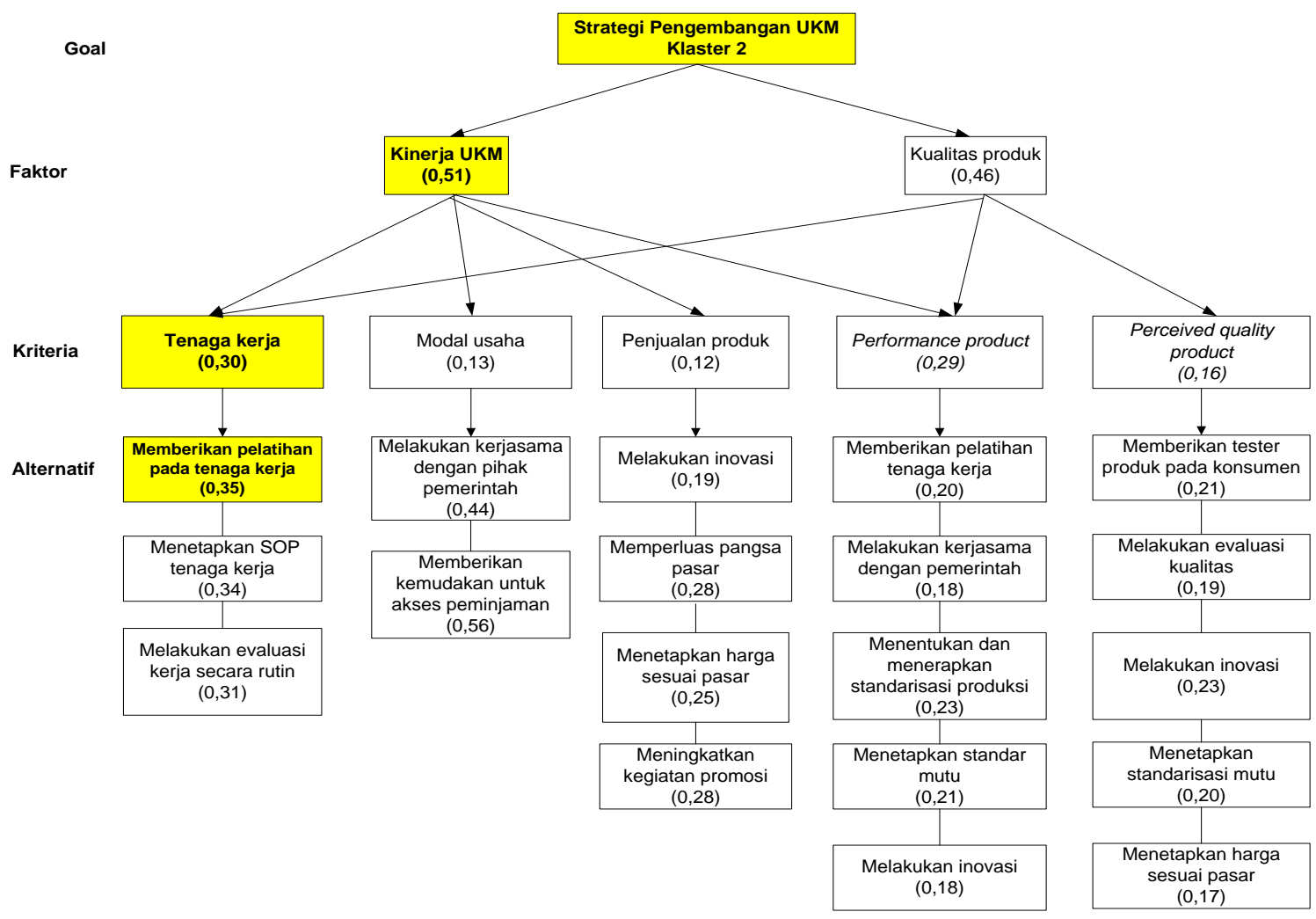

Gambar 3. Hirarki dan prioritas strategi pengembangan ukm klaster 2 di Kabupaten Lamongan 


\section{SIMPULAN}

Pengembangan klaster berdasarkan kinerja dan kualitas produk pada UKM emping jagung di Kabupaten Lamongan membentuk sejumlah 2 klaster. Pada pengembangan UKM klaster 1 faktor yang gunakan kualitas produk $(0,57)$, kriteria performance product $(0,32)$ sehingga alternatif yang digunakan menentukan dan menerapkan standarisasi produk $(0,27)$. Pada pengembangan UKM klaster 2 faktor yang berpengaruh kinerja UKM $(0,51)$, kriteria tenaga kerja $(0,30)$ sehingga alternatif yang digunakan adalah memberikan pelatihan tenaga kerja $(0,35)$.

\section{DAFTAR PUSTAKA}

Abdollahbeigi, -B., Shahidisadr, -M. 2013 packaging innovation effects in enhance sales. International Journal of Business, Economics and Law. 2(1), 1-5. https://www.ijbel.com/previous-issue /june-2013/vol-2-issue-1-june-2013/

Alexandersson, -A., Fridolf, -A. 2015. The process of distributor selection among smesa multiple-case study in the healthcare sector. https://gupea.ub.gu. se/bitstream/2077/39886/1/gupea_207 7_39886_1.pdf

Bakhtiar, B., Bima Murti Wijaya, A. and Dwi Cahyono, H., 2016. Pengembangan Sistem Analisis Akademis Menggunakan Olap Dan Data Clustering Studi Kasus: Akademik Universitas Sebelas Maret Surakarta. Jurnal Teknologi \& Informasi ITSmart, $\quad 4(1), \quad 1-11$. https://doi.org/10.20961/its.v4i1. 1748

Iwuagwu, -O. 2011. The cluster concept: will nigeria's new industrial development strategy jumpstart the country's industrial takeoff?. Afro Asian Journal of Social Sciences. 2(2), 1-24. http://www.onlineresearchjournals.com /aajoss/art/75.pdf

Kane, -A., Nagar, -J. 2012. Determining the number of clusters for a k-means clustering algorithm. Indian Journal of Computer Science and Engineering (IJCSE), 3(5), 670-672. https://www.ijcse.com/ docs/INDJCSE12-03-05-080.pdf

Kodinariya, -T., Makwana, -P. 2013. Review on determining number of cluster in kmeans clustering. International Journal of Advance Research in Computer Science and Management Studies, 1(6), 90-95. http://www.ijarcsms.com/docs/pape r/volume1/issue6/V1I6-0015.pdf

Purnima, -B., Arvind, -K., 2014. Ebk-means: a clustering technique based on elbow method and k-means in WSN. International Journal of Computer Applications. 105(9), 17-24. https:// doi.org/10.5120/18405-9674

Akindipe, -O., 2014. The role of raw material management in production operations. International Journal of Managing Value and Supply Chains. 5(3), 37-44. https://doi.org/10.5121/ijmvsc.2014. 5303

Nugrahaning, -S.A. 2012. Penentuan alternatif lokasi pengembangan kawasan agroindustri berbasis komoditas pertanian unggulan di Kabupaten Lamongan. Jurnal Teknik ITS, 1(1), C33-C37. https://doi.org/ 10.12962/j23373539.v1i1.925

Setyaningsih, -S. 2012. Using cluster analysis study to examine the successful performance entrepreneur in indonesia. Procedia Economics and Finance. The Authors, 4(Icsmed), 286298. https://doi.org/10.1016/S22125671(12)00343-7

Susanti, -N. 2018. Perancangan e-marketing umkm kerajinan tas. Simetris. 9(1), 717722. https://doi.org/10.24176/simet. v9i1.2042

Syakur, -M.A. 2018. Integration k-means clustering method and elbow method for identification of the best customer profile cluster. IOP Conference Series: Materials Science and Engineering, 336(1). https://doi.org/ 10.1088/1757899X/336/1/012017

Tmava, -Q., Peci, -F., Luboteni, -G. 2013. The role of banks in small and medium enterprises financing: a case study from Kosovo. International Journal of Economics and Finance. 5(12), 94-104. https://doi.org/10.5539/ijef.v5n12p94

Wang, -Y.M., Chin, -K.S., 2011. Fuzzy analytic hierarchy process: A logarithmic fuzzy preference programming methodology. International Journal of Approximate Reasoning. Elsevier Inc. 52(4), 541-553. https://doi.org/10.1016/j.jar.2010.12.004 
Jurnal Teknologi Pertanian Vol. 20 No. 2 [Agustus 2019] 85-94

Strategi Pengembangan Klaster Berdasarkan Kinerja dan Kualitas [Sari dkk]

Zhang, -X., Ma, -W., Chen, -L., 2014. New similarity of triangular fuzzy number and its application. The Scientific World
Journal. 2014, 1-7. https://doi.org/10.

$1155 / 2014 / 215047$ 